\title{
Translation Studies: What's in a name?
}

\author{
Luc van Doorslaer \\ University of Tartu \\ KU Leuven \\ Stellenbosch University
}

\begin{abstract}
This contribution starts from the observation that translation and translation studies (TS) seem to be perceived in a more vocational way than adjacent practices and disciplines. In the beginning of the $21^{\text {st }}$ century, digitization and transmedial production led to a diversification of text-modifying and text-adapting practices, which have also affected the romantic concepts of authorship as well as the dominance of the aesthetics of opposition. A strong tendency within TS is already including these new developments and practices in research, and as such broadening the scope and the object of the discipline. However, there is also a tendency opposing this expansion and advocating the narrower object exclusively linked to the traditional practices of translating and interpreting proper. The name discussion about the discipline has been ongoing for a long time, but is now put in a different perspective due to these societal and disciplinary changes and relations.
\end{abstract}

\section{Keywords}

media history of translation, transmediality, institutionalization, aesthetics of opposition, aesthetics of identity, authorship, post-translation studies, disciplinary perception

\section{Introduction: the eternal "theory vs. practice" discussion}

All scholars in our discipline will recognize scenes similar to the following one. Someone asks about your profession and you answer: "I'm a professor in translation studies". The reaction is: "Oh, interesting. In what languages?" Or the main alternative reaction: "Oh, interesting! And are you then also a translator yourself?" I have checked this out with several colleagues of mine. The professor in literary studies was never asked: "Are you then also a writer yourself?" The professor in theater studies was never asked: "Are you then also an actor yourself?" The professor in political sciences was never asked: "Are you then also a politician yourself?"

My default answer is usually something like: "I'd love to. Unfortunately, the professorship is already more than a full-time job". The different reactions when discussing translation studies (TS) tell us something about the understanding and the reputation of translation in society. Much more than literature, theater or politics, translation is, first of all, associated with or experienced as a practice----which undoubtedly all four of them are.

For TS scholars who grew up with James Holmes" "The name and nature of translation studies" (Holmes 1988[1972]) as one of the absolute seminal texts, the addition of 'studies' automatically redirects the perspective to the meta level of humanities research. However, this is clearly not necessarily the case in the non-TS world. Despite the growing institutionalization of the discipline for several decades and in many regions worldwide, this institutionalization is still very unevenly spread, even with regard to the academic research content: "[W]hile 
academic and governmental authorities may recognize translator training as being entitled to specific schools, with a few exceptions such as Spain or Austria in Europe and China in the Far East, they do not recognize its research component as deserving a dedicated institutional label" (Gile 2012, 79).

TS not only has a history of internal frictions and discussions about the relationship between the practice and the reflection on it----the most explicit example being the famous 'dialogue' (at moments a dialogue of the deaf) between so called theory and practice (Chesterman and Wagner 2002). Moreover, there also is the external perception in society at large, where the dominance of the practice over the reflection seems to be considerable.

In a recent article, Zwischenberger (2019) argues that these internal and external perceptions cannot be separated. Since translation is more associated with a practice than with a scholarly field, the perception of this practice in the outside world is largely determined by practitioners. Unfortunately, the images spread by translators' professional associations often confirm the illusion of a stable sense and meaning that can be neutrally transferred. This idea is also strengthened by the practice of some technological translation tools that are based on a reductionist view on translation and equivalence (van Doorslaer 2018: 224). On the other hand, translation research has clearly shown that these assumptions are mostly outdated and unrealistic:

Modern TS has long since abandoned restricted notions of equivalence between a source and its target text, or the idea of a stable sense that is to be transferred correctly. Yet the field of practice is still governed by such assumptions and propagates them actively. The reasons for this are manifold and range from wanting to depict the translating and interpreting professions as innocent to presenting translators and interpreters as trustworthy professionals steered by fidelity, accuracy, and neutrality. These buzzwords sell well----and as already noted the meta-discourses produced by professional associations are not only geared to their members but also to clients. These meta-texts, then, serve as marketing tools for the profession. (Zwischenberger 2019, 265)

Commercial, marketing and image-related motivations are inevitably a more determining factor in the considerations and sensitivities of the translation practitioner than of the translation researcher. That is a direct consequence of their different roles in society, and here is where the huge gap between theory and practice lies. Such tension is not a fundamental problem, it also exists in the relationship that adjacent disciplines have with their related practice field. I tend to agree with Zwischenberger when she states that the traditional explanatory framework of translation practice "is particularly damaging to the discipline because it perpetuates perceptions of 'translation proper' and consequently also of TS as outdated" $(2019,266)$. On the other hand, many events and colloquia have already been organized, and are still being organized, where both professional groups, the translation scholars and the translators, meet. This is certainly the case in Europe, it would be interesting to investigate to what extent there are continental or cultural differences in this regard. Very often the same viewpoints are exchanged, mainly illustrating the different motivations and positions in society. Considerable progress is made when, during such meetings, agreement is reached about overcoming the black-and-white dichotomy of "theory vs. practice". Reducing TS to 'theory' is not only a denial of the importance of descriptive and applied TS in Holmes's map (in the same seminal article Holmes 1988/172), but it also strongly underestimates the binding strength of those descriptive and applied approaches for translation practice. It is always good to talk, exchange 
experiences, and try to understand each other's position, but there are probably more productive approaches possible.

\section{The changing object of TS}

\subsection{Digitization and media history of translation}

The most fascinating developments are the changes in translation practice and the new perspectives this opens for TS. Twenty to thirty years ago, the growing scholarly interest in audiovisual translation (see for instance Remael 2010) was one of the first signs that traditional and static views on (often literary) translation, the unicity of authorship, and the monodirectional hierarchical relationship between source text and target text were fundamentally questioned by "the concepts of media and multimedia, the necessity of interdisciplinarity, the polysemiotic dimension of audiovisual media“" (Gambier \& Gottlieb 2001: cover text).

Central to that change in the translation activity is the transition from the era of the printed text to that of the digitized text. Both our concepts and practices of writing and reading have always been heavily determined by material conditions. From tablet over roll, codex and book to a digital computer text, the material circumstances co-established the ways of reading and writing. In communication studies, the impact of technical or technological conditions is very much present in mass media history writing (for instance in Chapman 2006). Even when just limited to the era of television, the differences between antenna, cable, satellite and digital viewing are obvious. In TS, however, only over the past decade there have been a few relatively modest attempts to approach the history of translation through a media perspective (such as Littau 2011).

According to Gambier (2020, forthcoming), a socio-historiography of TS urgently needs further steps in the description of a media history of translation. He already outlines how this could be (partly chronologically) built up: the parallels between collaborative translation in the Middle Ages and in our digitized era, the heyday of print culture from the Renaissance until the end of the $20^{\text {th }}$ century, and of course the change of mindset and a look at media interdependency and interaction nowadays.

A hypertext, materially and semantically open, takes over the print text, limited in its materiality but open semantically. The traditional division of labor between the production of a text, a film, a piece of music and their distribution is blurred with the Information and Communication Technology (ICT) easily accessible today. The collaboration in translating also changes the process. In some twenty to thirty years, ICT has transformed the concepts of text and book and our experience of reading, writing and translating. The translation act is now visible on the computer screen: readers (including other translators) can partake in the process and have the possibility to compare multiple translated versions, rather than just compare the source and target texts. (Gambier 2020, forthcoming)

It would certainly add value if such a proposal for a media history could be enhanced with nonWestern perspectives on the topic. The medial and modal transformations as well as their interactions are a new and exciting reality for TS, which inevitably brings the object and the approaches of the discipline closer to some of the translation-related work done in semiotics. 
In the department of Semiotics at the University of Tartu, a colleague of mine, Elin Sütiste, is running a project investigating the inter- and transmedial images of Hamlet in Estonian culture. Studying Hamlet in itself is not exactly innovative, one might think, but the transmediality dimension makes a huge difference. One chapter in Gentzler (2017), for instance, already illustrates how enriching it can be to study tradaptations and translational revisionings of Hamlet in China. Sütiste's corpus is still a work in progress, but it comprises verbal translations, stage productions, a movie, poems, music productions, paintings, graphic works, playbills, and reviews. Whereas earlier Hamlet research often focused on larger linguistic and/or cultural areas, technological developments also enhanced research possibilities for relatively small cultural areas.

Looking at translations from this perspective, including all translational offshoots, necessarily widens the concept of translation as well as our view on the phenomenon and practice. This broadening tendency has already been going on for some four decades, but is now strengthened and put in the spotlight because of the rapid transmedial developments. In general, this evolution has brought us "from a retrospective focus on non-change [...] to an approach that privileges dynamics and variation via expanding types of change, such as modal, cultural, media-related, social, and technological" (van Doorslaer 2018, 220). Sameness and equivalence as dominating prescriptions are replaced by difference and transformation as default options in a descriptive, reality-based framework. Obviously, this also hugely affects the role and position of the translator.

\subsection{Rehierarchizing types of aesthetics}

Authors such as Tymoczko (2007) have already expanded on the existing connection between the enlargement of the object of TS on the one hand, and the more powerful status of the translator on the other hand. This is also symbolically well represented by Apostolou (2009, in this case about the interpreter), where she suggests a more frequent use of Hermes as the symbol not only of inbetweenness and ambivalence, but also of inevitable manipulation. It is an illusion to believe that the translator can be a merely neutral being, for every textual change involves background, context and commitment. For sure, Hermes will have a near-Herculean task to gradually liberate the translator (and the interpreter as a specific professional type of translator) from that stigma of imposed neutrality. The stigma was long visible through reprimanding qualifications such as traduttore, traditore (the translator as traitor) or monodirectional views on translations as products involving 'loss'.

What might help, however, is that the centuries-old association with 'copying' can once again be approached in a more nuanced way. The famous distinction between the two types of aesthetics as suggested by the semiotician Juri Lotman elucidates this. The traditional secondhand image of the translator who 'only' copies is experienced as inferior in a period where the "aesthetics of opposition" is dominant, whereby innovation and 'originality' are the highest goods and copying is necessarily subordinate. Although many people nowadays believe that this is a universal and timeless value, nothing is less true, as Lotman made clear: "Throughout the history of art, artistic systems that associate aesthetic worth with originality are the exception rather than the rule" (Lotman 1977, quoted in Berger 1992, 51). The literary scholars Fokkema and Kunne-Ibsch also refer to Lotman when they apply this to periodization in literary history:

In the study of literary history, Lotman argues, one should distinguish between 'the aesthetics of identity' (estetika toždestva) and 'the aesthetics of opposition' (estetika 
protipostavlenija). The first is characteristic of folklore, the Middle Ages and Classicism, to which one could add the ancient Asiatic cultures. The aesthetics of opposition is typical of Romanticism, Realism and the Avant-garde. The 'aesthetics of identity' presupposes the identity or near-identity of the code of the sender with that of the receiver. (Fokkema \& Kunne-Ibsch, quoted in Kersenboom-Story 1987, 164)

The image of the translator as traitor, as a second-hand author and a generator of 'loss' is a construct strongly supported by the aesthetics of opposition since Romanticism. Concomitantly, originality as symbolized by the so called 'genius' of the unique author was glorified. In that sense, the status of author and that of translator behave like communicating vessels. The more strongly the unicity of the author's genius is constructed, the easier it will be to represent the translator as traitor and unsuccessful copier. By the way, this insight makes clearly visible why translators behave in a rather masochistic way when they take over the terminology of 'original' and 'translation'. It is a terminological pair perfectly expressing the logics of the aesthetics of opposition, putting the creation of the 'original' and idealized author high above the secondhand product of the translator. Especially given that for several decades now descriptive translation studies has been using the much more equal-value terms 'source text' and 'target text', it is remarkable to see that many translators continue to use a term pair that automatically downgrades the perception of their own work.

On the other hand, the law of communicating vessels obviously works both ways. Since postmodernism and its epistemological relativism, the author, too, has lost his romantic authority and his halo of originality. Every text is considered a link in an intertextual chain, it is always related to other texts and as such never genuinely original. Such interrelationship makes every text partly new, partly reproducing and adapting----a description which comes pretty close to the activity of a translator.

This development at the beginning of the $21^{\text {st }}$ century goes hand in hand with a boom of transmedial production and reproduction. Where appreciation is growing for the value of offshoots, spinoffs, rewritings, co-writings, adaptations, recontextualizations, etc., the glorification of the author's singularity is relativized, in some cases even ridiculed. The author's product and the translator's product both are small elements in a complex and interacting text production system that is multimodal and transmedial.

These two developments are mutually reinforcing and they fundamentally affect the relationship between the author and the translator. Relativizing the absoluteness and originality of the author upgrades the stature of other text producers such as rewriters, adapters, localizers and translators. Moreover, the ubiquity and normality of transmedial recreations merge forms of copying and creating. As a result, this perspective blurs the boundaries between the two activities, which could also be considered as the two main approaches of the translator. Despite the evidence of the impact of these two developments, it might take a while before this will be more broadly accepted. As Zwischenberger convincingly illustrates, the traditional ideals and illusions of faithfulness, exactness and stability of meaning are, for instance, deeply rooted in the professional associations' charters and codes of ethics. Instead of problematizing the muchmore-than linguistic complexity of the translator's work, such charters are based on moral obligations, and "the professional translator is portrayed as someone who has access to an author's intentions and thoughts" $(2019,265)$.

\subsection{Expanding or narrowing down}


The changed view on the scope of the translator's work is reflected in large parts of modern TS research. As Chesterman outlines in a recent article, nowadays we can discern "four major areas" of research which are not totally separate, "but rather reflect differences of primary focus, and overlaps are normal" $(2019,11)$ : 1 . linguistic research (for instance source text-target text relationships, forms of equivalence); 2. cultural research (for instance interculturality, power issues, ideology); 3. cognitive research (often based on newer methods such as eye-tracking and key-logging); and 4. sociological approaches (for instance agency, working conditions, networks). Most of these approaches start from a broader object for TS, certainly not limited to the traditional "translation proper" only. The object often explicitly includes the translator as well----not only in the sociological, but also in many cognitive and culturally-oriented approaches.

This substantial focus on the translator shows that TS is considerably informed by translation practice----more evidence that the "theory vs. practice"-dichotomy is outdated. However---and this is often much less taken notice of ----TS also affects translation practice, in particular the translator. The development of scholarly activity inevitably has social consequences for the translator's profession, as it raises its visibility and, in some cases, also status. Translators would be among the first beneficiaries of a stronger and broader institutionalization of TS throughout the world. Seen from that perspective, reducing TS to a vocational guidance tool, as is sometimes still assumed or demanded by professional translators, would actually be counterproductive for their own status. Or as I wrote on an earlier occasion: "Instrumentalizing reflection on translation merely to solve translation problems runs the risk of narrowing the activity down to its vocational dimensions, whereas the critical acceptance of additional theoretical reflection would also add value to their societal status and would raise selfawareness“" (van Doorslaer 2013, 80).

However, although there is a clear tendency in TS over the past decades to broaden the object of research, let us not forget that there are also currents in the discipline defending the exact opposite position. They generally defend the premise that TS should stick to its original core business of interlingual translation (practice) and exclude other text-modifying practices such as intralingual or intersemiotic translation. Earlier, I gave the example of a TS conference in Austria that labeled the tendency of going beyond translation proper as alarming (van Doorslaer 2018, 220-221). Recently a scholar like Brian Mossop has also repeatedly warned against such tendencies, as they would undermine the specificity of the discipline----and that specificity is essentially linked to the often criticized equivalence concept.

[...] something like the concept of equivalencing needs to be defended against the now commonplace references to the old notion of equivalence as dubious or passé. [...] Under the influence of literary and cultural studies, there has been too much emphasis in recent years on the non-equivalencing [p. 20] work of translators. While the ways in which translations inevitably differ from their sources is certainly of interest, it remains that most translators spend most of their time, with most texts, trying to make the translation mean what they think the source text means, rather than producing adaptations.

Equivalencing is a unique activity; its central presence in translators' language production distinguishes this work from that of all other kinds of writer. Too often one reads that translation is not about 'mere' equivalence, as if writing that is dominated by equivalencing were not interesting or glamorous enough to study, or as if there were nothing more to learn about it. As all practicing translators know, changing meaning 
(whether deliberately or accidentally) is easy whereas preserving it is precisely what is so difficult. (Mossop 2016, 19-20)

This quote illustrates several of the elements described above. The reasoning is essentially based on a concept of stable meaning that can be 'preserved'. It explicitly starts from a translation practice as it has existed (and certainly still partly exists), without taking into account the modal and medial diversification of professional translation activities because of growing transmediality. Mossop strongly advocates an exclusively vocational orientation of TS, only related to translation schools and not studied as a practice that deserves wider attention because of its intellectual and societal complexity, its recreative potential in its different shapes, and its growing centrality in the text production reality of the $21^{\text {st }}$ century. "The theoretical study of translation has been and should continue to be firmly rooted in translation schools, with the goal of describing and explaining what translators do and what translations do" (Mossop 2016, 20).

\section{The name imperfection}

Every disagreement about the content of the term 'translation' also links to the related object and scope discussion of TS. Only the colleagues who are convinced that there has been no fundamental change in the approach to translation do not feel the need to problematize this. For them TS continues to relate to translation practice, translation schools and interlingual translation only. All the others see many complicating factors, not least because of the modal and medial developments as described above.

Despite the development, also in TS, towards English becoming the only real international publishing language, especially this discipline cannot afford to forget about the different perception in different languages. In English, the term 'translation studies' was and is used in several ways: on the one hand as a very specific term, dealing with research on written translation only; on the other hand as an umbrella term, not only covering translation proper, but also related text-modifying practices such as interpreting, adaptation, and localization---hence book titles such as the Encyclopedia of Translation Studies or the Handbook of Translation Studies, even when these books include several entries on interpreting or adaptation as well. A language like German, for instance, can solve it differently. As a more technical term it uses a third concept, Translation (pronounced the German way), covering both Übersetzen (written translation) and Dolmetschen (oral translation). Other languages still have different terms and interactions between semantic fields.

Especially in the Anglophone world, there is a growing popularity of the term 'T\&I studies', mentioning interpreting next to translation. This is partly a consequence of the double use of TS in English. When 'translation' is experienced as written translation only, it is understandable that interpreting researchers feel excluded. However, this is not the case if 'translation' is used as an umbrella term. On the other hand, the addition of the I in the discipline's name also indicates the relative autonomization of interpreting studies as a subfield. Although the number of researchers is still relatively low, the past decade has certainly seen innovative and methodologically specific research related to interpreting practices only. In that sense, making the I explicitly visible is deserved and sympathetic. However, there are also two main reasons why this name addition can be questioned, or at least problematized. 
First of all, this name evolution might obscure the important epistemological connectedness of the two practices, the fact that "[p]henomenologically [...] the two activities and their pertinent research domains share an enduring common basis" (Grbić and Wolf 2012, 7). It is legitimate to ask to what extent this separated presentation is beneficial or instead harmful for the external image of the discipline. The second reason is partly related to the first one. Given the recent digital developments in transmedial translating, rewriting and adapting as described above, it seems not without risks to stress separate practices in the name of a discipline. As many more new and related practices are emerging, there might soon be proponents of such activities who believe that their relative autonomization, too, could be acknowledged in the discipline's name. Many publications in TS already deal with adaptation for instance, or localization, or rewriting. A development towards T\&I\&A\&L\&R studies is not really a heartening path to follow. This may seem a ridiculing point of view, but it is not. It only consistently pursues the logics of stressing separate practices in the name of an academic discipline. There might be a good reason, mutatis mutandis, why a discipline like media studies prefers an umbrella term and does not call itself newspaper\&radio\&TV\&online studies.

There might even be a third reason, which is a full combination of the first two. We started this article by describing how translation is already experienced as more practical and vocational than many similar text-producing activities. The name 'T\&I Studies' confirms that. Again, there will certainly be researchers who advocate this, and prefer that the discipline be limited to exactly those two practices only, the translation and interpreting schools and the corresponding professional associations. However, it also means that the considerable number of research and researchers in favor of broadening the discipline's scope and object is excluded. In a way, it is also an invitation to other disciplines for confining T\&I Studies to exactly those practical and exclusively linguistic matters, leaving broader views to other fields. This is actually already done quite often in other disciplines. An example is the viewpoint of Italiano, who distinguishes between "the praxis-oriented cosmos of translation and interpreting studies, on the one hand, and culture-oriented, literary studies, on the other" (Italiano 2016: 4).

The discussion and evolution are ongoing and undecided. A central issue is how exactly to signal the interrelatedness of so many different approaches studying similar phenomena. Except for TS in its umbrella meaning, the proponents of a broader object and scope of the discipline have not come up with an encompassing name yet. Nonetheless, it seems inevitable that TS has to reach out to other (sub)disciplines dealing with other, but somehow similar text-modifying practices. This has already partly happened in exchanges with adaptation studies, for instance. This may be a less institutionalized field concentrating mainly on film adaptation, but where several researchers, including authoritative ones such as Linda Hutcheon, have acknowledged the growing commonalities with TS: "Just as there is no such thing as a literal translation, there can be no literal adaptation. [...] This newer sense of translation comes closer to defining adaptation as well' (Hutcheon 2006, 16). More explicit dialogues between the two related disciplines can for instance be found in Cattrysse (2014) or in van Doorslaer \& Raw (2016).

A fundamental question to be investigated is how the exact common ground between all these subfields and practices can be described. Is it the transfer of information or the transformation of information? In an era where transdisciplinary connections are stimulated and challenged, this knowledge field could no doubt contribute in an interesting way, as an illustration of blurred borders between both practices and disciplines.

The name issue in itself is already typical for this dynamic development. Many discussions center exactly around the concept of translation that is experienced as too narrow. The purely 
linguistic, equivalence-based interpretation is a reason for many authors to suggest 'broader' terms----whereas they could also consider 'translation' in its broader sense. In that sense, it is also a strategic or rhetorical move: first you narrow down an existing concept, in order to be able to then come up with a widening alternative term. According to Gambier, the multitude of such attempts also shows that the term 'translation' is sometimes perceived as part of the problem.

The word translation seems to suffer from a bad reputation. It is often replaced by or competes with other terms, such as localization, adaptation, versioning, transediting, language mediation, and transcreation. Although this proliferation of labels does not take place in all languages and societies, the fact that they have surfaced and gained currency can hinder our comprehension and appreciation of the breadth and scope of the markets. It can also complicate the purview of the discipline: How are we to understand what the object of investigation really is in translation studies? How broadly can the definition of the term be extended to encompass the evolving communication situations and new hierarchies implied beyond the labels? (Gambier 2016, 888)

An interesting example where the narrowing down of the concept is applied to the discipline of TS is Edwin Gentzler's book Translation and rewriting in the age of post-translation studies (Gentzler 2017). ${ }^{1}$ Gentzler is one of the main proponents of expanding the concept of translation as well as the discipline. In this book, he eloquently substantiates and illustrates that fascinating plea (with which I agree, by the way)----but in a rather radical way, as the term 'post-TS' can also be read as the declaration of the death of a discipline. However, to justify the concept of post-TS, he narrows down the activities and achievements of TS in quite a radical way. TS is described as a field that is "still restricted, primarily focused on written texts and two-way comparisons, and neglecting pre- and post-translation effects" $(2017,2)$ or that is mainly dealing with "[f]inding better methods to describe, inventory, or assess translations" $(2017,3)$. There would be ample evidence for showing that a considerable amount of TS research over the past decades has already dealt with similar approaches as suggested in the book. That different perception may on the one hand be connected to our different academic settings (USA and Europe) with diverging developments in TS. Compared to several European or Asian contexts, "the United States is a country with remarkably few translator-training institutions [...] and scant development of Translation Studies as envisaged in the descriptive paradigm" (Pym 2010, 159). Gentzler is aware of that himself when he writes that his research "is derived from studying translation within the borders of the United States" $(2017,7){ }^{2}$ On the other hand, however, this approach is also an intellectual processing similar to the attempts that replace translation by 'expanded' concepts, but in this case applied to the discipline. In any case, all these expansion attempts function as signals for translation and TS that many things are on the move in the fields of text-modifying practices and the ways in which they are scholarly approached.

\footnotetext{
1 Together with Edwin Gentzler, in September 2018 I participated in a round table discussion under the title 'Has translation studies reached its limits? On the potential of post-translation studies' during the conference Translation, Interpreting and Culture: Old Dogmas, New Approaches (Nitra, Slovakia). I here include a small part of the interesting discussion we had during that round table.

2 Though it seems that not all US colleagues agree with such presentation of affairs either. In a review of the book, Henson writes that "there is nothing radical, certainly nothing novel, in Gentzler's proposition. The Center for Translation Studies at the University of Texas Dallas has been dedicated to such a transdisciplinary approach to translation for decades" (Henson 2018: 74).
} 


\section{Conclusion}

In this contribution, I have tried to show that the field of translation and TS has developed far beyond the stage of the simple opposition "theory vs. practice". Both concepts not only inform each other, but also witness, and co-determine, important changes in the field due to technological and aesthetic changes. The blurring of borders is also an ongoing process between TS and adjacent research fields that deal with other text-modifying practices. This will inevitably affect the seemingly never-ending debate on the name of the discipline. TS has gone through a remarkable evolution in half a century, but will also be subject to new societal, technological and disciplinary developments. From that angle, it is important that TS scholars actively reflect about the name and the label, but even more so about the position of this type of research in relation to adjacent disciplines.

\section{Acknowledgment}

This work was supported by the University of Tartu Astra Project Per Aspera and grant number PHVLC19917. I would like to express my gratitude to Yves Gambier and Douglas Robinson for their valuable critical feedback on a draft version of this article. 


\section{References}

Apostolou, Fotini. 2009. "Mediation, manipulation, empowerment. Celebrating the complexity of the interpreter's role." Interpreting 11 (1): 1-19. doi 11.1075/intp.11.1.02apo

Berger, Arthur Asa. 1992. Popular Culture Genres: Theories and Texts. Newbury Park: Sage.

Cattrysse, Patrick. 2014. Descriptive adaptation studies: epistemological and methodological issues. Antwerpen: Garant.

Chapman, Jane. 2006. Comparative Media History. Cambridge: Polity Press.

Chesterman, Andrew. 2019. "Consilience or fragmentation in Translation Studies today?" Slovo: Baltic accent 10 (1), 9-20. doi: 10.5922/2225-5346-2019-1-1

Chesterman, Andrew, and Emma Wagner. 2002. Can Theory Help Translators? A Dialogue Between the Ivory Tower and the Wordface. Manchester: St. Jerome.

Gambier, Yves. 2016. "Rapid and radical changes in translation and translation studies." International Journal of Communication 10, 887-906. doi 1932-8036/20160005

Gambier, Yves. 2020 (forthcoming). "Approaches to a historiography of translation studies." In Resituating Translation Studies: Temporal, geographical and disciplinary dynamics of theorization, ed. by Luc van Doorslaer and Ton Naaijkens. Leiden: Brill.

Gambier, Yves, and Henrik Gottlieb (eds). 2001. (Multi)Media Translation: Concepts, practices, and research. Amsterdam: John Benjamins.

Gentzler, Edwin. 2017. Translation and rewriting in the age of post-translation studies. Abingdon: Routledge.

Gile, Daniel. 2012. "Institutionalization of Translation Studies." In Handbook of Translation Studies, vol. 3, ed. by Yves Gambier and Luc van Doorslaer, 73-80. Amsterdam: John Benjamins.

Grbić, Nadja, and Michaela Wolf. 2012. "Common grounds in translation and interpreting (studies)." In Handbook of Translation Studies, vol. 3, ed. by Yves Gambier and Luc van Doorslaer, 7-16. Amsterdam: John Benjamins.

Henson, George. 2018. [Review of] Translation and Rewriting in the Age of PostTranslation Studies, Translation Review, 102 (1): 73-77.

Holmes, James S. 1988 [1972]. "The name and nature of translation studies.” In Translated! Papers on literary translation and translation studies, ed. by James S. Holmes and Raymond van den Broeck, 67-80. Amsterdam: Rodopi.

Hutcheon, Linda. 2006. A theory of adaptation. London: Routledge.

Italiano, Federico. 2016. Translation and Geography. London: Routledge. 
Kersenboom-Story, Saskia C. 1987. Nityasumangalī: Devadasi Tradition in South India. Delhi: Motilal Banarsidass.

Littau, Karin. 2011. "First steps towards a media history of translation." Translation Studies 4 (3): 261-81. DOI: 10.1080/14781700.2011.589651

Mossop, Brian. 2016. “'Intralingual translation': a desirable concept?” Across Languages and Cultures 17 (1): 1-24. DOI: 10.1556/084.2016.17.1.1

Pym, Anthony. 2010. Exploring Translation Theories. Abingdon: Routledge.

Remael, Aline. 2010. “Audiovisual translation.” In Handbook of Translation Studies, vol. 1, ed. by Yves Gambier and Luc van Doorslaer, 12-17. Amsterdam: John Benjamins.

Tymoczko, Maria. 2007. Enlarging Translation, Empowering Translators. Manchester: St. Jerome.

van Doorslaer, Luc. 2013. "Impact of translation theory." In Handbook of Translation Studies, vol. 4, ed. by Yves Gambier and Luc van Doorslaer, 77-83. Amsterdam: John Benjamins.

van Doorslaer, Luc. 2018. "Bound to Expand. The Paradigm of Change in Translation Studies." In Moving Boundaries in Translation Studies, ed. by Helle V. Dam, Matilde Nisbeth Brøgger, and Karen Korning Zethsen, 220-230. Abingdon: Routledge.

van Doorslaer, Luc, and Laurence Raw. 2016. "Adaptation studies and translation studies: very interactive yet distinct." In Border Crossings: Translation Studies and other disciplines, ed. by Yves Gambier and Luc van Doorslaer, 189-204. Amsterdam: John Benjamins.

Zwischenberger, Cornelia. 2019. "From inward to outward: the need for translation studies to become outward-going." The Translator 25 (3): 256-268. DOI:

10.1080/13556509.2019.1654060 